\title{
Complexo multienzimático e probióticos na dieta de frangos de corte
}

\author{
Multienzyme complex and probiotics in broiler diet
}

\author{
GEWEHR, Clóvis Eliseu ${ }^{1}$; ROSNIECEK, Marcos ${ }^{1}$; FOLLMANN, Diogo Davi ${ }^{1}$; \\ CEZARO, Ana Maira de ${ }^{1}$; GERBER, Marcelo Silva ${ }^{1}$; SCHNEIDER, Aline Félix ${ }^{1}$
}

\author{
${ }^{1}$ Universidade do Estado de Santa Catarina, Centro de Ciências Agroveterinárias, Departamento de \\ Produção Animal e Alimentos, Lages, Santa Catarina, Brasil. \\ *Endereço para correspondência: a2ceg@cav.udesc.br
}

\section{RESUMO}

Objetivou-se avaliar o desempenho zootécnico de frangos de corte alimentados com dietas com inclusão de complexo multienzimático e probióticos e sua inclusão com a redução de $3 \%$ nos níveis de energia e proteína. Foram utilizados 630 frangos de corte, no período de 14 a 42 dias de idade, submetidos a três dietas experimentais: dieta conforme exigências nutricionais (controle); dieta conforme exigências com inclusão de complexo multienzimático e probióticos $(100 \mathrm{~g} / \mathrm{ton})$, e dieta com redução de $3 \%$ dos níveis de energia metabolizável (EM) e proteína bruta $(\mathrm{PB})$ em relação às exigências com inclusão do aditivo $(100 \mathrm{~g} /$ ton $)$. Observou-se maior $(\mathrm{P}<0,05)$ consumo de ração nas dietas com $3 \%$ de redução nos níveis de energia e proteína durante os períodos entre 14$21,35-42$ e 14-42 dias, enquanto que a dieta com adição do complexo levou a consumo semelhante $(\mathrm{P}>0,05)$ ao controle em todos os períodos analisados. As dietas com redução de energia e proteína diferiram do controle $(\mathrm{P}<0,05)$ em relação à conversão alimentar e peso vivo somente aos 21 dias de idade. No ganho de peso e índice bioeconômico não foram observadas diferenças $(\mathrm{P}>0,05)$. Nas fases de crescimento e terminação, a inclusão do complexo multienzimático e probióticos em dietas para frangos de corte, formuladas conforme exigência nutricional, não melhora o desempenho zootécnico. Com redução em 3\% dos níveis de energia e proteína das rações em relação às exigências e inclusão do complexo multienzimático e probióticos, o consumo aumenta, entretanto o peso vivo, conversão alimentar, ganho de peso e índice bioeconômico não se alteram.

Palavras-chave: aditivos, avicultura, desempenho, enzimas

\section{SUMMARY}

The aim of this study was to evaluate the growth performance of broiler chickens fed diets with inclusion of probiotics and multienzyme complex and its inclusion with a $3 \%$ reduction in the levels of energy and protein. 630 broilers were used, since 14 up to 42 days old, submitted to three experimental diets: diet as nutritional requirements (control); diet as required with inclusion of multienzyme complex and probiotics ( $100 \mathrm{~g} / \mathrm{ton})$, and diet with $3 \%$ reduction in levels of metabolizable energy and crude protein requirements with inclusion of the additive (100 g/ton). Was observed increase ( $\mathrm{P}$ $<0.05)$ of feed intake in diets with $3 \%$ reduction in the levels of protein and energy during periods of 14-21, 35-42 and 14-42 days, while the diet with added complex led to similar consumption $(\mathrm{P}>0.05)$ to the control in all periods analyzed. Diets with reduced energy and protein differed from control $(\mathrm{P}<0.05)$ in feed conversion ratio and live weight only at 21 days age. There were no differences $(\mathrm{P}>0.05)$ in gain of weight and bio-economic index. During the growing and finishing phases, the inclusion of the multienzyme complex and probiotics in diets for broilers formulated as nutritional requirement does not improve animal performance. With $3 \%$ reduction in the levels of protein and energy rations in relation to the requirements and inclusion of multienzyme complex and probiotics consumption increases, however, the body weight, feed conversion, weight gain and bio-economic index do not change.

Keywords: additives, enzymes, performance, poultry 


\section{INTRODUÇ̃̃̃O}

As aves produzem enzimas que auxiliam os processos digestivos, porém não possuem a capacidade de digerir totalmente alguns nutrientes, como as fibras e, por isso, precisam de enzimas exógenas que auxiliem no processo da digestão (KHATTAK et al., 2006). A utilização de enzimas exógenas na dieta pode contribuir para o aumento da eficiência alimentar das aves devido à melhoria da digestibilidade de produtos considerados de baixa qualidade e a diminuição da perda de nutrientes fecais, sendo possível reduzir os níveis nutricionais da ração através da inclusão de complexos enzimáticos, resultando em retorno econômico (TORRES et al., 2003) Tal situação torna-se ainda mais relevante quando destaca-se que a alimentação representa cerca de $70 \%$ do custo de produção de um lote de frangos. Neste sentido, o emprego de ferramentas para redução deste custo deve ser objetivado pelos nutricionistas. Buscando aperfeiçoar os processos digestivos, além da utilização de enzimas exógenas, probióticos vêm sendo testados nas dietas de frangos de corte. Segundo Teixeira et al. (2003), probióticos podem ser definidos como microrganismos benéficos adicionados à dieta das aves com o objetivo de promover o equilíbrio da microflora intestinal. Esses aditivos têm sido apontados como possíveis alternativas para a substituição dos promotores de crescimento, evitando-se assim, a possibilidade de resíduos de antibióticos na carne (RIGOBELO et al., 2011).

Objetivou-se avaliar o desempenho zootécnico e o índice bioeconômico de frangos de corte alimentados com dietas com inclusão de um complexo composto por enzimas e probióticos, e sua inclusão com a redução de $3 \%$ nos níveis de energia e proteína.

\section{MATERIAL E MÉTODOS}

$\mathrm{O}$ experimento foi realizado em aviário de alvenaria aberto, com telas antipássaros e cortinas plásticas nas laterais, sendo utilizados 630 frangos de corte, machos, da linhagem COBB 500, criados inicialmente em pinteiro único com campânula termostática para manutenção da temperatura de conforto das aves e alimentados com dieta inicial. De zero a 14 dias de idade, as aves receberam dietas experimentais, formuladas conforme as recomendações de Rostagno et al. (2005), entretanto, em função de logística e ambiência do aviário, nesse período, as 210 aves de cada tratamento foram criadas em três pinteiros distintos de $2,5 \mathrm{~m}^{2}$ de diâmetro, cada um equipado com uma campânula termostática para manutenção da temperatura de conforto. Aos 14 dias de idade, fez-se a transferência aleatória das aves de cada tratamento para 30 boxes de $2,1 \mathrm{~m}^{2} / \mathrm{cada}$, onde foram criadas até 42 dias de idade. Cada box compôs uma unidade experimental e foi equipado com um comedouro tubular e um bebedouro pendular. Água e ração foram fornecidos ad libitum durante $\mathrm{o}$ período experimental. Os frangos foram distribuídos em um delineamento inteiramente casualizado, com 10 repetições de 21 aves cada. As dietas fornecidas às aves de um a 42 dias eram isonutritivas, com exceção aos níveis de EM, PB e aminoácidos na dieta redução. 
Rev. Bras. Saúde Prod. Anim., Salvador, v.15, n.4, p.907-916 out./dez., 2014 http://www.rbspa.ufba.br ISSN 15199940

Tabela 1. Ingredientes e níveis de energia metabolizável (EM) e proteína bruta (PB) das rações experimentais

\begin{tabular}{|c|c|c|c|c|}
\hline \multirow{2}{*}{ Fase } & \multirow{2}{*}{ Ingrediente } & \multicolumn{3}{|c|}{ Tipos de ração } \\
\hline & & Controle $(\mathrm{Kg})$ & Adição (Kg) & Redução (Kg) \\
\hline \multirow{13}{*}{$\begin{array}{c}\text { Inicial } \\
14 \text { a } 21 \text { dias }\end{array}$} & Milho & 549,5 & 549,2 & 591,8 \\
\hline & Farelo de soja $(45 \%)$ & 358,6 & 358,7 & 337,2 \\
\hline & Óleo & 37,9 & 38,0 & 16,9 \\
\hline & Núcleo $\mathrm{min} / \mathrm{vit}^{1}$ & 54,0 & 54,0 & 54,0 \\
\hline & Complexo enzimático & - & 0,1 & 0,1 \\
\hline & Total & 1.000 & 1.000 & 1.000 \\
\hline & EM (kcal/kg) & 3.000 & 3.000 & 2.910 \\
\hline & PB (\%) & 20,79 & 20,79 & 20,17 \\
\hline & $\mathrm{Ca}(\%)$ & 0,88 & 0,88 & 0,88 \\
\hline & $\mathrm{P}(\%)$ & 0,44 & 0,44 & 0,44 \\
\hline & Sódio (\%) & 0,21 & 0,21 & 0,21 \\
\hline & Lisina digestível (\%) & 1,146 & 1,146 & 1,196 \\
\hline & Metionina digestível & 0,447 & 0,447 & 0,440 \\
\hline \multirow{13}{*}{$\begin{array}{l}\text { Crescimento } \\
22 \text { a } 35 \text { dias }\end{array}$} & Milho & 586,77 & 586,5 & 628,4 \\
\hline & Farelo de soja (45\%) & 317,83 & 317,9 & 297,5 \\
\hline & Óleo & 45,4 & 45,5 & 24,0 \\
\hline & Núcleo $\min /$ vit $^{1}$ & 50,0 & 50,0 & 50,0 \\
\hline & Complexo enzimático & - & 0,1 & 0,1 \\
\hline & Total & 1000,0 & 1000 & 1000 \\
\hline & EM (kcal/kg) & 3100 & 3100,1 & 3006,7 \\
\hline & PB (\%) & 19,25 & 19,25 & 18,67 \\
\hline & $\mathrm{Ca}(\%)$ & 0,82 & 0,82 & 0,82 \\
\hline & $\mathrm{P}(\%)$ & 0,41 & 0,41 & 0,41 \\
\hline & Sódio (\%) & 0,20 & 0,20 & 0,20 \\
\hline & Lisina digestível (\%) & 1,073 & 1,073 & 1,073 \\
\hline & Metionina digestível & 0,429 & 0,429 & 0,423 \\
\hline \multirow{13}{*}{$\begin{array}{l}\text { Terminação } \\
36 \text { a } 42 \text { dias }\end{array}$} & Milho & 622,4 & 622,2 & 665,5 \\
\hline & Farelo de soja (45\%) & 280,7 & 280,7 & 259,4 \\
\hline & Óleo & 46,9 & 47,0 & 25,0 \\
\hline & Núcleo min/vit ${ }^{1}$ & 50,0 & 50,0 & 50,0 \\
\hline & Complexo enzimático & - & 0,1 & 0,1 \\
\hline & Total & 1000,0 & 1000,0 & 1000 \\
\hline & EM (kcal/kg) & 3149,8 & 3150,1 & 3055,0 \\
\hline & PB (\%) & 17,86 & 17,86 & 17,25 \\
\hline & $\mathrm{Ca}(\%)$ & 0,76 & 0,76 & 0,76 \\
\hline & $\mathrm{P}(\%)$ & 0,37 & 0,37 & 0,37 \\
\hline & Sódio (\%) & 0,19 & 0,19 & 0,19 \\
\hline & Lisina digestível (\%) & 1,017 & 1,017 & 0,965 \\
\hline & Metionina digestível & 0,407 & 0,407 & 0,401 \\
\hline
\end{tabular}

${ }^{\mathrm{I}}$ Núcleo formulado para atender as exigências nutricionais recomendadas por Rostagno et al. (2005).

Durante o período de avaliação, as aves foram submetidas a três dietas experimentais, em três fases distintas (inicial de 14 a 21 dias; crescimento de
22 a 35 dias e terminação de 35 a 42 dias), descritas na Tabela 1, sendo uma dieta (dieta controle) formulada conforme as recomendações de 
Rostagno et al. (2005); uma segunda dieta teve a inclusão à dieta controle um aditivo alimentar composto pela associação de um complexo multienzimático e probióticos na quantidade de $100 \mathrm{~g} / \mathrm{t}$ de ração (dieta adição); e uma terceira dieta teve a redução de $3 \%$ nos níveis de energia metabolizável (EM-kcal/kg) e proteína bruta $(\mathrm{PB} \%)$ em relação à dieta controle, e a inclusão do mesmo aditivo na quantidade de $100 \mathrm{~g} / \mathrm{t}$ de ração (dieta redução). A composição do complexo de enzimas e probióticos está descrita na Tabela 2 .

Tabela 2. Concentração de enzimas e probióticos contidos no aditivo utilizado nas rações experimentais de frangos de corte

\begin{tabular}{lccc}
\hline \multicolumn{2}{c}{ Enzimas (Unidade / Kg) } & Probióticos (CFU/Kg) \\
\hline Protease & $1 \times 10^{6}$ & Lactobacilus acidofilus & $9 \times 10^{10}$ \\
Amilase & $7,5 \times 10^{5}$ & Bifidobacterium thermophilum & $9 \times 10^{10}$ \\
Celulase & $4 \times 10^{5}$ & Bifidobacterium longum & $9 \times 10^{10}$ \\
Peptinase & $2 \times 10^{5}$ & Streptococus faecium & $9 \times 10^{10}$ \\
Lipase & $3 \times 10^{5}$ & & \\
Lactase & $5 \times 10^{3}$ & & \\
Xilanase & $4 \times 10^{4}$ & & \\
Fitase & $2,2 \times 10^{2}$ & & \\
\hline
\end{tabular}

Foi avaliado o consumo de ração (kg/ave) de cada parcela através do fornecimento de uma quantidade préestabelecida de ração, sendo as sobras pesadas e contabilizadas ao final de cada semana. O peso médio das aves $(\mathrm{kg})$ foi aferido semanalmente, através da pesagem individual e perfazendo a média de cada parcela experimental. $\mathrm{O}$ ganho de peso $(\mathrm{kg})$ foi determinado através da subtração entre o peso médio das aves das parcelas ao final de cada semana e o peso da semana anterior. A conversão alimentar $(\mathrm{kg} / \mathrm{kg})$ foi obtida através da relação entre o consumo de ração e o ganho de peso médio semanal de cada parcela. Para analisar a viabilidade econômica do efeito da adição do complexo multienzimático e probióticos sobre o desempenho dos frangos, foi utilizado o índice bioeconômico (IBE), desenvolvido por Guidoni et al. (1994), o qual foi calculado semanalmente pela seguinte fórmula: $\mathrm{IBE}=$ Ganho de peso $-(\mathrm{R} \$$ $\mathrm{kg}$ de ração/R $\$ \mathrm{~kg}$ ave viva) x consumo de ração por ave.

As análises estatísticas foram realizadas a partir dos dados de todas as unidades experimentais incluídas nas três dietas estudadas, de 14 a 42 dias, em 10 repetições de 21 aves em cada unidade experimental, de acordo com o delineamento inteiramente casualizado. Foi adotado um modelo de análise de variância e as médias que diferiram foram analisadas pelo teste de Duncan. Em todas as análises, utilizou-se o procedimento MIXED (LITTELL et al., 2006) do software computacional estatístico SAS version 9.1.3 (SAS Institute, 2003). Para todas as análises efetuadas, foi considerado o nível mínimo de $5 \%$ de significância.

$\mathrm{O}$ projeto foi submetido ao Cetea (Comitê de Ética em Experimentação Animal), da Udesc, e aprovado sob o número de protocolo 1.02.13. 


\section{RESULTADOS E DISCUSSÃO}

No consumo de ração (Tabela 3), observou-se que a redução de $3 \%$ dos níveis de EM e PB com adição do complexo nas rações resultaram em maior $(\mathrm{P}<0,05)$ consumo na maioria dos períodos analisados (entre 14 a 21; 28 a 35,35 a 42 e entre 14 a 42 dias) em relação às demais dietas. Somente entre 21 a 28 dias não foram observadas diferenças $(\mathrm{P}>0,05)$ entre as dietas.

Tabela 3. Consumo de ração e ganho de peso de frangos de corte alimentados com dietas contendo complexo multienzimático e probióticos e, redução de $3 \%$ dos níveis de energia metabolizável (EM-kcal/kg) e proteína bruta (PB\%) com o mesmo aditivo

\begin{tabular}{llllllllllll}
\hline \multirow{2}{*}{$\begin{array}{l}\text { Período } \\
\text { (dias) }\end{array}$} & \multicolumn{4}{c}{ Consumo de ração (kg/ave) } & \multicolumn{5}{c}{ Ganho peso (kg/ave) } \\
\cline { 2 - 11 } & Controle & Adição & Redução & $\begin{array}{l}\text { CV } \\
(\%)\end{array}$ & $P$ & Controle & Adição & Redução & $\begin{array}{l}\text { CV } \\
(\%)\end{array}$ & $P$ \\
\hline 14 a 21 & $0,730^{\mathrm{b}}$ & $0,733^{\mathrm{b}}$ & $0,748^{\mathrm{a}}$ & 1,53 & 0,0001 & 0,529 & 0,532 & 0,527 & 1,29 & 0,13 \\
21 a 28 & 1,102 & 1,094 & 1,108 & 2,52 & 0,32 & 0,695 & 0,687 & 0,673 & 4,13 & 0,09 \\
28 a 35 & $1,201^{\text {ab }}$ & $1,170^{\mathrm{b}}$ & $1,209^{\mathrm{a}}$ & 2,66 & 0,02 & 0,787 & 0,784 & 0,791 & 3,74 & 0,88 \\
35 a 42 & $1,632^{\mathrm{b}}$ & $1,640^{\mathrm{b}}$ & $1,706^{\mathrm{a}}$ & 2,83 & 0,01 & 0,784 & 0,808 & 0,814 & 4,11 & 0,45 \\
14 a 42 & $5,654^{\mathrm{b}}$ & $5,631^{\mathrm{b}}$ & $5,767^{\mathrm{a}}$ & 1,18 & 0,03 & 2,846 & 2,850 & 2,832 & 1,26 & 0,19 \\
\hline
\end{tabular}

Letras desiguais nas linhas nas respectivas avaliações diferem estatisticamente $(\mathrm{P}<0,05)$.

Este maior consumo na dieta redução pode ser justificado pela necessidade das aves em ingerir maior quantidade de ração para suprir suas necessidades de energia e proteína. Já na dieta adição, com inclusão do complexo multienzimático e probióticos, verificouse ausência de diferenças $(P>0,05)$ em relação ao controle, o que pode indicar que o aditivo não apresenta efeitos evidenciados sobre o consumo de ração. Utilizando um complexo enzimático composto pelas enzimas alfa-amilase $(2000 \mathrm{U} / \mathrm{g})$, protease $(6000 \mathrm{U} / \mathrm{g})$ e xilanase $(800 \mathrm{U} / \mathrm{g})$, Torres et al. (2003) observaram que ocorreu redução no consumo de ração em rações isonutritivas. Entretanto, em comparação com uma dieta com redução de $5 \%$ da EM e PB, ocorreu aumento do consumo de ração em relação a uma dieta controle formulada conforme exigência.

Não foram observadas diferenças $(\mathrm{P}>0,05)$ no ganho de peso das aves entre as dietas testadas, em todos os períodos analisados (Tabela 3). É possível reduzir em 3\% os níveis de EM e PB, em dietas com adição de complexo de enzimas e probiótico, em relação às exigências, sem efeitos deletérios ao ganho de peso das aves. Por alterar a digestibilidade dos ingredientes, o complexo multienzimático e probióticos pode ter compensado o ganho de peso das aves que receberam a dieta com redução de $3 \%$ nos níveis de energia e proteína. É importante frisar que o aditivo testado continha oito enzimas, agindo tanto sobre os componentes enérgicos quanto sobre os proteicos da dieta, resultado em melhora na digestibilidade geral da ração. As enzimas atuam em reações específicas, por isso a utilização de complexos nos quais é possível agrupar diferentes tipos enzimáticos torna-se passível de maior efeito benéfico, quanto à utilização dos nutrientes das 
dietas, em comparação com produtos isolados (VIANA et al., 2009).

Resultados obtidos por Zanella et al. (1999) ao avaliarem o efeito da suplementação das enzimas amilase, protease e xilanase em rações à base de milho e soja para frangos de corte de 1 a 45 dias de idade, indicaram melhora no desempenho das aves com adição das enzimas. Já com níveis decrescentes de energia, não houve diferença no desempenho zootécnico, indicando que a melhoria trazida pela utilização de enzimas compensou o conteúdo energético mais baixo das dietas. Um fator que talvez possa explicar a divergência do resultado deste experimento é o fato que não foi reduzida apenas a EM, mas também a PB. Sobre este aspecto, supõe-se que as enzimas proteolíticas não tenham $o$ efeito desejado sobre o consumo, e que este pode aumentar para suprir a necessidade de aminoácidos. Neste contexto, é importante ressaltar que as dietas receberam as mesmas quantidades de aminoácidos sintéticos via núcleo, com valores tabelados. Para as aves que receberam dieta com redução de 3\% nos níveis de energia e proteína, verificouse pequenas diferenças nos níveis de lisina e metionina em relação as demais dietas testadas. Destaca-se que as dietas utilizadas neste experimento eram compostas majoritariamente por milho e farelo de soja, que são nutrientes de ótima digestibilidade. Faz-se necessário testar a inclusão desses aditivos em dietas com nutrientes de baixas digestibilidade, para os quais o complexo pode resultar em melhorias aos processos digestivos e, consequentemente, ao desempenho zootécnico das aves. Cowieson \& Adeola (2005), utilizando as enzimas xilanase, amilase, protease (XAP) e fitase em diferentes combinações de enzimas para frangos de corte de um a 28 dias de idade com dietas à base de milho e farelo de soja com níveis de energia, $\mathrm{Ca}$ e $\mathrm{P}$ mais baixos (controle negativo), resultou que a adição de 100 $\mathrm{mg} / \mathrm{kg}$ de XAP ou fitase melhorou o ganho de peso em 7 e 6,2\% respectivamente; e quando as enzimas foram utilizadas em combinação, o ganho de peso melhorou em 14\%. Observou-se que a combinação das enzimas nas dietas à base de milho e soja melhora o desempenho de frangos de corte alimentados com dietas com baixos níveis nutricionais. $\mathrm{O}$ trabalho desenvolvido por Silveira et al. (2010) utilizando um complexo enzimático composto pelas enzimas fitase, protease, xilanase, $ß$-glucanase, celulase, amilase e pectinase em frangos de um a 21 dias de idade não observou diferenças no desempenho das aves.

O menor peso vivo e conversão alimentar das aves observadas aos 21 dias nas dietas com redução dos níveis de energia e proteína, em relação às demais, pode ser atribuída ao fato de que, nessa fase, o complexo multienzimático não foi capaz de refletir sua eficiência em compensar a redução dos níveis nutricionais (Tabela 4). Na conversão alimentar, entre 14 e 21 dias, o aditivo em dietas com redução dos níveis de energia e proteína também não foi capaz de propiciar resultado semelhante $(\mathrm{P}<0,05)$ à dieta controle.

Quando adicionado à dieta sem redução dos níveis nutricionais, observou-se que houve semelhança com o controle. Afora a primeira semana de avaliação, nas demais, observa-se que é possível a redução dos níveis de EM e PB em 3\% nas rações com a adição do complexo em relação às respectivas exigências recomendadas em tabela, sem que o peso vivo e a conversão alimentar sejam afetados. Faz-se necessário evidenciar que a quantidade de óleo incluída nas dietas pode contribuir para melhores resultados quanto ao desempenho 
zootécnico, visto seu efeito extracalórico. (PUCCI et al., 2003). Pode-se observar que nas dietas formuladas sem redução dos níveis de energia e proteína, a quantidade de óleo incluída foi muito semelhante à dieta controle e, entre estes dois grupos, não foram observadas diferença no desempenho das aves. No entanto, nas dietas com redução de 3\% nos níveis de energia e proteína, a quantidade de óleo incluída foi muito inferior à dieta formulada conforme as exigências nutricionais, reduzindo a possibilidade de um resultado referente à inclusão de óleo na dieta. Logo, nessa situação, os resultados benéficos podem ser atribuídos ao uso do complexo de enzimas e probióticos.

Tabela 4. Peso vivo ( $\mathrm{kg})$ e conversão alimentar $(\mathrm{kg} / \mathrm{kg})$ semanal de frangos de corte alimentados com dietas contendo complexo multienzimático e probióticos e redução de 3\% dos níveis de energia metabolizável (EM-kcal $/ \mathrm{kg})$ e proteína bruta (PB\%) com o mesmo aditivo

\begin{tabular}{lllllllllll}
\hline \multirow{2}{*}{$\begin{array}{l}\text { Idade } \\
\text { (dias) }\end{array}$} & Controle & Adição & Redução & $\begin{array}{l}\text { CV } \\
(\%)\end{array}$ & $P$ & Controle & Adição & Redução & $\begin{array}{l}\text { CV } \\
(\%)\end{array}$ & $P$ \\
\hline 21 & $1,031^{\mathrm{a}}$ & $1,036^{\mathrm{a}}$ & $1,021^{\mathrm{b}}$ & 1,37 & 0,01 & $1,38^{\mathrm{b}}$ & $1,38^{\mathrm{b}}$ & $1,41^{\mathrm{a}}$ & 1,89 & 0,002 \\
28 & 1,755 & 1,762 & 1,751 & 1,06 & 0,23 & 1,59 & 1,60 & 1,65 & 3,64 & 0,001 \\
35 & 2,530 & 2,538 & 2,512 & 1,02 & 0,15 & 1,53 & 1,49 & 1,53 & 4,45 & 0,46 \\
42 & 3,349 & 3,348 & 3,324 & 1,25 & 0,45 & 2,10 & 2,08 & 2,11 & 4,83 & 0,49 \\
\hline
\end{tabular}

Letras desiguais nas linhas nas respectivas avaliações diferem estatisticamente $(\mathrm{P}<0,05)$.

Observa-se que na literatura também são encontrados resultados controversos. O trabalho de Torres et al. (2003) corrobora com os resultados do presente trabalho para peso vivo e conversão alimentar, observando semelhante peso vivo aos 42 dias em aves recebendo rações com uso de enzimas em relação a uma ração formulada conforme as exigências. Também não encontraram diferenças no peso das aves com redução de $5 \%$ dos níveis de energia e proteína em relação a uma ração formulada conforme as exigências. Com relação à conversão alimentar, esses autores concluíram que esta aumenta com redução de $5 \%$ nos níveis de energia e proteína. Silveira et al. (2010) também não encontraram diferença na conversão alimentar de frangos de um a 21 dias de idade. Trabalho que teve resultados divergentes ao do presente estudo é o de
Zanella et al (1999) em que, utilizando frangos de um a 45 dias de idade, concluíram que a suplementação enzimática melhorou o peso corporal e a conversão alimentar em 1,9 e 2,2\%, respectivamente. É importante ressaltar que o complexo utilizado neste ensaio continha probióticos associados. Gil de los Santos \& Turnes (2005) destacam a contraposição de resultados em desempenho zootécnico quanto a utilização de probióticos e citam ainda uma resistência do setor avícola em adotar seu uso. A utilização de probióticos pode não resultar em efeitos benéficos quando as aves não estão submetidas a desafios sanitários (LODDI et al., 2000). A discussão entre trabalhos científicos quanto ao uso de probióticos torna-se difícil, já que os aditivos apresentam composições e dosagens práticas diferentes, além de que as condições ambientais interferem 
Rev. Bras. Saúde Prod. Anim., Salvador, v.15, n.4, p.907-916 out./dez., 2014 http://www.rbspa.ufba.br ISSN 15199940

diretamente no efeito destes (BORATTO et al., 2004). Pêssoa et al. (2012) enfatiza a importância da dosagem correta dos probióticos e da presença do desafio sanitário para se comprovar a eficácia destes aditivos. A citação acima é confirmada por Loddi et al (2000), os quais não recomendam a utilização de aditivos a base de Enterococcus faecium em condições de baixo desafio sanitário. São necessários estudos que testem a inclusão destes complexos em dietas de aves submetidas a alto desafio sanitário, onde efeitos benéficos mais expressivos poderão ser observados. Além disso, é importante reassaltar que o uso de aditivos como probióticos e prebióticos vem destacando-se, pois não apresentam toxicidade e não induzem a resistência bacteriana (RAMOS et al., 2011). Com a busca por redução do uso dos antimicrobianos como promotores de crescimento na avicultura, as pesquisas de novas alternativas são fundamentais.

Não foram observadas diferenças $(\mathrm{P}<0,05)$ no índice bioeconômico (Tabela 5) entre as dietas.

Tabela 5. Índice Bioeconômico ( $\mathrm{g}$ ) de frangos de corte alimentados com dietas contendo complexo multienzimático e probióticos, e redução de $3 \%$ dos níveis de energia metabolizável (EM-kcal/ $\mathrm{kg})$ e proteína bruta $(\mathrm{PB} \%)$ com o mesmo aditivo

\begin{tabular}{|c|c|c|c|c|c|}
\hline \multirow{2}{*}{ Idade (dias) } & \multicolumn{4}{|c|}{ Índice Bioeconômico (IBE) } & \multirow{2}{*}{$P$} \\
\hline & Controle & Adição & Redução & $\mathrm{CV}(\%)$ & \\
\hline 14 a 21 & 0,216 & 0,214 & 0,219 & 3,04 & 0,381 \\
\hline 21 a 28 & 0,236 & 0,230 & 0,229 & 10,06 & 0,782 \\
\hline 28 a 35 & 0,290 & 0,295 & 0,296 & 10,33 & 0,922 \\
\hline 35 a 42 & 0,135 & 0,143 & 0,151 & 26,53 & 0,708 \\
\hline
\end{tabular}

Destaca-se que o índice bioeconômico leva em consideração o preço das matérias primas e do frango vivo apenas quando do momento da inferência. Uma alteração nos valores de cada item em uma formulação de ração, por exemplo, ou com o preço do kg pago pelo frango, pode alterar o resultado obtido. Neste aspecto, é válido para fazer uma análise específica quando do período da avaliação.

Conclui-se que a inclusão do complexo multienzimático e probiótico em dietas para frangos de corte, formuladas conforme as exigências nutricionais, não altera o desempenho das aves. A redução de 3\% dos níveis de EM e $\mathrm{PB}$ em relação às exigências nutricionais com adição do complexo multienzimático e probiótico, não altera $o$ peso vivo, conversão alimentar, ganho de peso, entretanto aumenta o consumo de ração. $O$ índice bioeconômico de frangos de corte alimentados com inclusão do complexo multienzimático e probiótico em rações formuladas de acordo com a exigência nutricional e com redução de $3 \%$ dos níveis de EM e PB não é alterado.

\section{REFERÊNCIAS}

BORATTO, A.J.; LOPES, D.C.; OLIVEIRA, R.F.M.; ALBINO, L.F.T.; SÁ, L.M.; OLIVEIRA, G.A. Uso de antibiótico, de probiótico e de homeopatia em frangos de corte criados 
Rev. Bras. Saúde Prod. Anim., Salvador, v.15, n.4, p.907-916 out./dez., 2014 http://www.rbspa.ufba.br ISSN 15199940

em ambiente de conforto, inoculados ou não com Escherichia coli. Revista

Brasileira de Zootecnia, v.33, n.6, p.1477-1485, 2004 .

COWIESON, A.J.; ADEOLA, O.

Carboydrases, protease, and phytase have na additive beneficial effect in nutritionally marginal diets for broiler chicks. Poultry Science, v.84, p.18601867, 2005.

\section{GUIDONI, A.L. Alternativas para} comparar tratamentos envolvendo o desempenho nutricional animal. 1994. 105p. Tese (Doutorado) - Escola Superior de Agricultura "Luiz de Queiroz", Universidade de São Paulo, Piracicaba.

GIL DE LOS SANTOS, J.R.; TURNES, C.G. Probióticos em avicultura. Ciência Rural, v.35, n.3, p.741-747, 2005.

KHATTAK, F.M., PASHA, T. N.; HAYAT, Z.; MAHMUD, A. Enzymes in poultry nutrition. Journal of Animal and Plant Sciences, v.16, n.1-2, p.1-7, 2006.

LITTELL, R.C.; MILLIKEN, G.A.; STROUP, W.W.; WOLFINGER, R.D.; SCHABENBERGER, O. SAS for mixed models. $2^{\text {nd }}$ ed. Cary: SAS Institute, 2006. 813p.

LODDI, M.M.; GONZALES, E.; TAKITA, T.S.; MENDES, A.A.; ROÇA. R. DE O. Uso de probiótico e antibiótico sobre o desempenho, o rendimento e a qualidade de carcaça de frangos de corte. Revista Brasileira de Zootecnia, v.29, n.4, p.1124-1131, 2000.

PESSÔA, G.B.S.; TAVERNARI, F. DE C.; VIEIRA, R.A.; ALBINO, L.F.T. Novos conceitos em nutrição de aves. Revista Brasileira de Saúde e Produção Animal [online], v.13, n.3, p.755-774, 2012.
PUCCI, L.E.A; RODRIGUES, P.B.; FREITAS, R.T.F DE, BERTECHINI, A.G.; CARVALHO, E.M. Níveis de óleo e adição de complexo enzimático na ração de frangos de corte. Revista Brasileira de Zootecnia, v.32, n.4, p.909- 917, 2003.

RAMOS, L. DE S.N.; LOPES, J.B.; SILVA, S.M.M. DE S.; SILVA, F.E.S.; RIBEIRO, M.N. Desempenho e histomorfometria intestinal de frangos de corte de 1 a 21 dias de idade recebendo melhoradores de crescimento. Revista Brasileira de Zootecnia, v.40, n.8, p.1738-1744, 2011 .

RIGOBELO, E. C.; MALUTA, R.P.; ÁVILA, F.A. Desempenho de frangos de corte suplementadas com probiótico. Ars Veterinaria, v.27, n.2, 111-115, 2011.

ROSTAGNO, H.S.; ALBINO, L.F.T.; DONZELE, J.L.; GOMES, P.C.; OLIVEIRA, R.F. DE; LOPES, D.C.; FERREIRA, A.S.; BARRETO, S.L. DE T.; EUCLIDES, R.F. Tabelas Brasileiras para aves e suínos: composição de alimentos e exigências nutricionais. Viçosa, MG. Universidade Federal de Viçosa. 2005.186p

SAS Institute Inc. SAS/SAT. Version 9.1.3. Cary, 2003.

SILVEIRA, M.H.D. DA; ZAN USSO, J.T.; ROSSI, P.; RUTZ, F.; ANCIUTI, M.A.; ZAUK, N.F.; RIBEIRO, C.L.G.; BRUM, P.A.R.; NUNES, J.K. Efeito da peletização em dietas contendo complexo enzimático para frangos de corte. Ciência Animal Brasileira, v.11, n.2, p.326-333, 2010. 
Rev. Bras. Saúde Prod. Anim., Salvador, v.15, n.4, p.907-916 out./dez., 2014 http://www.rbspa.ufba.br ISSN 15199940

TEIXEIRA, A.S.; CAVALCANTI, J. DOS S.; OST, P.R.; SCHOULTEN, N.A. Probióticos em rações para frangos de corte utilizando farinha de carne e ossos com diferentes níveis de contaminação bacteriana. Ciência e Agrotecnologia, v.27, n.4, p.927-933, 2003

TORRES, D.M.; TEIXEIRA, A.S.; RODRIGUES, P.B.; BERTECHINI, A.G.; FREITAS, R.T.F. DE; SANTOS, E.C. DOS. Eficiência das enzimas amilase, protease e xilanase sobre o desempenho de frangos de corte.

Revista Ciência e Agrotecnologia, v.27, n.6, p.1401-1408, 2003.

VIANA, M.T. DOS S.; ALBINO, L.F.T.; ROSTAGNO, H.S.; SILVA, E.A. da; MESSIAS, R. K. G.; PEREIRA, J.P.L. Efeito do uso de enzimas sobre o desempenho e metabolismo de poedeiras. Revista Brasileira de Zootecnia, v.38, n.6, p.1068-1073, 2009.

ZANELLA, I.; SAKOMURA, N.K.; SILVERSIDES, F.G.; FIQUEIRDO, A.; PACK, M. Effect of enzyme supplementation of broiler diets based on corn and soybeans. Poultry Science, v.78, p.561-568, 1999.

Data de recebimento: 19/03/2014

Data de aprovação: 03/11/2014 